\title{
Estrutura do capital das PME da indústria transformadora portuguesa: uma análise com dados em painel
}

\section{Capital structure of Portuguese manufacturing industry SMEs: an analysis with panel data}

\author{
Fernanda Matias \\ Universidade do Algarve - ESGHT, Centro de Estudos e Formação Avançada em Gestão e Economia - CEFAGE \\ Campus da Penha, 8005-139 Faro, Portugal, mfmatias@ualg.pt
}

\section{Celísia Baptista}

Universidade do Algarve - ESGHT, Centro de Estudos e Formação Avançada em Gestão e Economia - CEFAGE Campus da Penha, 8005-139 Faro, Portugal, cbaptist@ualg.pt

\section{Leonor Salsa}

Universidade do Algarve - ESGHT, Centro de Estudos e Formação Avançada em Gestão e Economia - CEFAGE Largo Engo Sárrea Prado, 21, 8501-859 Portimão, Portugal, mlsalsa@ualg.pt

\section{Resumo}

Este trabalho investiga os determinantes da estrutura de capital de 1.488 PME portuguesas pertencentes à indústria transformadora. Os resultados da análise de dados em painel de 2004-2011 sugerem que as teorias do trade-off e da pecking-order não são mutuamente exclusivas na explicação das decisões de estrutura de capital.

Os resultados obtidos mostram que as PME de maior dimensão parecem utilizar mais dívida e as que dispõem de menos ativos colaterizáveis necessitam de contrair mais dívida de curto prazo. As empresas mais rendíveis tendem a utilizar menos dívida de longo prazo. Por sua vez, as PME têm dificuldade em financiar o seu crescimento com dívida de médio e longo prazo. Ao contrário do previsto, observou-se uma relação positiva entre a especificidade dos ativos, entendida como a estrutura tecnológica da produção, e o endividamento. As PME mais antigas tendem a apresentar estruturas de capital menos endividadas. A crise financeira parece ter tido impacto na forma de financiamento das PME.

Palavras-chave: Estrutura de capital, pequenas e médias empresas, indústria transformadora, dados em painel.

\begin{abstract}
This paper studies the determinants of capital structure of 1.488 small and medium size Portuguese firms belonging to the manufacturing sector. The analysis results of a 2004-2011 panel data suggest that trade-off and pecking order theories are not mutually exclusive in explaining capital structure decisions.

The results obtained suggest that greater size firms employ more debt regardless of its maturity and those with less level of collateral use more short-term debt. More profitable firms tend to use less long-term debt. In turn, small and medium firms have difficulties in financing growth with long-term debt. Unlike what was expected, we observed a positive association between asset specificity, seen as technological structure of production, and debt. Older firms tend to have less leveraged capital structures. The financial crisis seems to have had impact on financing of small and medium Portuguese firms.
\end{abstract}

Keywords: Capital structure, small and medium firms, manufacturing sector, panel data.

\section{Introdução}

A decisão sobre a estrutura de capital da empresa é uma das mais importantes no âmbito da gestão financeira. Os trabalhos de Modigliani e Miller (MM) sobre estrutura de capital $(1958,1963)$ têm estimulado um extenso debate sobre a estrutura ótima de capital e os seus determinantes.

A estrutura de capital das micro, pequenas e médias empresas (PME) tem sido investigada em diferentes contextos. Alguns estudos centram-se na especificidade de um país em concreto: Portugal (Serrasqueiro, Armada \& Nunes, 2011), Espanha (Sogorb-Mira, 2005; López-Gracia \& Sogorb-Mira, 2008), Bélgica (Heyman, Deloof \& Ooghe, 2008), Reino Unido (Chittenden, Hall \& Hutchinson, 1996; Jordan, Lowe \& Taylor 1998; Michaelas, Chittenden \& Poutziouris, 1999), Holanda (Degryse, Goeij \& Kappert, 2012), Estados Unidos (Constant, Osteryoung \& Nast, 1991; Cole, 2013), Austrália (Holmes \& Kent, 1991; Cassar \& Holmes, 2003), Irlanda (Bhaird \& Lucey, 2010). Outros estudos pesquisam esta temática comparando diversos países (Hall, Hutchinson \& Michaelas 2004; Beck, Demirgüç-kunt \& Maksimovic, 2008; Mateev, Poutziouris \& Ivanov, 2013). Outros têm analisado os determinantes da estrutura de capital exclusivamente na indústria transformadora (Voulgaris, Asteriou \& Agiomirgianakis, 2002; Kim, Hesmati \& Aoun, 2006; Zhang, 2010; Bartholdy, Mateus \& Olson, 2012).

0 principal objetivo deste trabalho consiste em investigar os principais determinantes da estrutura de capital das PME da indústria transformadora portuguesa, setor que não tem sido objeto de intenso estudo. Os resultados serão discutidos no contexto das teorias da estrutura de capital, principalmente a teoria do trade-off e a teoria da pecking-order.

As PME assumem particular importância no seio da economia portuguesa. Em 2012, o seu número era de 352.596, representando $99,7 \%$ das sociedades não financeiras, $71,5 \%$ do emprego e $56,3 \%$ do Valor Acrescentado Bruto (INE, 2014). Neste estudo, considera-se uma amostra de 1.488 PME e o período compreendido entre 2004 e 2011. Como método de estimação, adota-se a regressão linar múltipla de dados em painel.

Os resultados obtidos mostram que as PME de maior dimensão parecem utilizar mais dívida e as que dispõem de menos ativos colaterizáveis necessitam de contrair mais dívida de curto prazo. As empresas mais rendíveis tendem a 
utilizar menos dívida de longo prazo. Por sua vez, constatase que as PME têm dificuldade em financiar o seu crescimento com dívida de médio e longo prazo.

Este estudo não sustenta a poupança fiscal não associada ao endividamento e a volatilidade como determinantes da estrutura de capital das PME. Ao contrário do previsto, observou-se uma relação positiva entre a especificidade dos ativos, entendida como a estrutura tecnológica da produção, e o endividamento. As PME mais antigas tendem a apresentar estruturas de capital com menor endividamento. No geral os resultados sugerem que as teorias do trade-off $\mathrm{e}$ da pecking-order não são mutuamente exclusivas na explicação das decisões de estrutura de capital das PME da indústria transformadora portuguesa.

O estudo apresenta uma breve revisão da investigação teórica e empírica e as hipóteses da pesquisa na secção 2 . Na secção 3 expõe-se a metodologia adotada. Os resultados são apresentados na secção 4. Por último, na secção 5 encontramse as conclusões e as implicações desta pesquisa.

\section{Revisão da literatura e hipóteses de investigação}

Volvidos mais de cinquenta anos desde que MM (1958) publicaram o seu estudo sobre a irrelevância da estrutura do capital no valor da empresa em situação de mercados perfeitos e completos, observa-se que a literatura teórica e empírica é bastante extensa. A derrogação dos pressupostos do modelo de MM (1958) contribuiu para o surgimento de diversas teorias explicativas da variação dos rácios de dívida entre as empresas, particularmente a consideração da tributação das empresas (MM, 1963), da tributação das pessoas singulares (Miller, 1977; DeAngelo \& Masulis, 1980), dos custos de falência (Kraus \& Litzenberger, 1973; Scott, 1976), dos custos de agência (Jensen \& Meckling, 1976; Jensen, 1986) e da informação assimétrica (Myers \& Majluf, 1984; Myers, 1984). Embora não seja consensual, as teorias que atualmente dominam o debate sobre estrutura de capital no âmbito das PME são a teoria do trade-offe a teoria da pecking-order.

A teoria do trade-off defende que as empresas procuram atingir um rácio ótimo da estrutura de capital através do equilíbrio entre benefícios e custos da dívida (Bradley, Jarrel \& Kim, 1984). Os benefícios da dívida incluem a dedutibilidade fiscal dos juros (MM, 1963) e a redução dos custos de agência do capital próprio (Jensen, 1986). Por outro lado, existem variáveis que levam as empresas a adotar níveis de endividamento mais moderados, como sejam os custos esperados de falência que serão maiores para empresas com menos ativos tangíveis, os custos de agência de empresas com reduzidos níveis de fluxos de caixa disponíveis, os impostos sobre o rendimento das pessoas singulares e formas substitutas do benefício fiscal decorrente dos juros, por exemplo, depreciações e amortizações do exercício (DeAngelo \& Masulis, 1980).

A teoria da pecking-order, proposta por Myers (1984) e Myers e Majluf (1984), assenta essencialmente no conceito de informação assimétrica entre gestores e investidores externos, mas tambémem considerações de agência (Jensen \& Meckling, 1976) e de sinalização (Ross, 1977). De acordo com esta teoria, as empresas financiam a sua atividade segundo uma hierarquia de fontes. Assim, as empresas optam inicialmente por fundos próprios, fonte com menor grau de informação assimétrica. Em caso de insuficiência de recursos, recorrerão ao endividamento e, por último, ao capital próprio. Consequentemente, esta teoria não prevê uma estrutura ótima de capital, antes defende que a estrutura de capital é o resultado de decisões de angariação de recursos de acordo com uma hierarquização de fontes. Ang (1991), Holmes e Kent (1991) e Michaelas et al. (1999) realçaram a pertinência da teoria da pecking-order no contexto das PME.

Estas teorias sugerem hipóteses testáveis sobre determinantes da estrutura de capital que nalguns casos são contraditórias, conforme se observará. No âmbito da indústria transformadora têm sido estudadas empiricamente diversas variáveis, que neste estudo serão investigadas no contexto da realidade portuguesa, nomeadamente dimensão, tangibilidade, rendibilidade, oportunidades de crescimento, poupança fiscal não associada ao endividamento, volatilidade, especificidade e idade.

\section{Dimensão}

De acordo com a teoria do trade-off a dimensão da empresa está positivamente associada com o nível de dívida (Scott, 1976). As empresas de maior dimensão tendem a possuir maior diversificação de atividades, o que contribui para diluir o nível de risco dos credores (Ang, 1992) e manifestam empiricamente menor probabilidade de falência (Cole, 2013).

0 problema da assimetria informacional entre os agentes internos e externos à empresa torna-se particularmente severo nas empresas de pequena dimensão devido à fraca qualidade da informação financeira disponibilizada (LópezGracia \& Aybar-Arias, 2000), o que agudiza os seus problemas de agência (Barnea, Haugen \& Senbet, 1981). Consequentemente, as pequenas empresas terão mais facilidade em endividarem-se a curto prazo (Chittenden et al., 1996). A teoria da pecking-order prevê uma relação positiva entre a dívida e a dimensão da empresa, embora a teoria original não fizesse referência à dimensão. Tal como em Hall et al. (2000; 2004), Degryse et al. (2012) e Mateev et al. (2013), sugerem-se as seguintes relações entre o endividamento e a dimensão.

Hipótese 1a: A dimensão da empresa está positivamente associada com a dívida de longo prazo.

Hipótese 1b: A dimensão da empresa está negativamente associada com a dívida de curto prazo.

\section{Tangibilidade}

As empresas com um nível de tangibilidade mais elevado disporão de mais ativos colaterizáveis. Harris e Raviv (1990) defenderam que as empresas com maior valor de ativo tangível têm maior valor de liquidação e, por sua vez, maior capacidade de endividamento. Acresce que os ativos tangíveis também poderão ser utilizados para reduzir os problemas de agência porque conferem segurança aos mutuantes caso surjam conflitos de interesses entre os proprietários e os gestores (Jensen \& Meckling, 1976). Por conseguinte, a teoria do trade-off prevê uma relação positiva entre o endividamento e a tangibilidade dos ativos.

Por sua vez, Harris e Raviv (1991) defendem que o problema de assimetria de informação é menos severo 
quando as empresas apresentam um maior valor de ativos tangíveis, o que poderá facilitar a concessão de crédito, nomeadamente crédito bancário. Esta constatação torna evidente a relação positiva prevista pela teoria da peckingorder entre o endividamento e a tangibilidade dos ativos.

Não obstante, considerando o princípio do equilíbrio financeiro entre o grau de liquidez das aplicações e de exigibilidade das origens de fundos, assume-se que a tangibilidade dos ativos poderá afetar de forma diferenciada a maturidade da dívida, conforme Hall et al. (2000; 2004), Sogorb-Mira (2005) e Mateev et al. (2013).

Hipótese 2a: Os ativos tangíveis estão positivamente associados com a dívida de longo prazo.

Hipótese 2b: Os ativos tangíveis estão negativamente associados com a dívida de curto prazo.

\section{Rendibilidade}

As duas teorias são contraditórias na sua predição quanto à relação entre o endividamento e a rendibilidade da empresa: a teoria do trade-off prevê uma relação positiva, enquanto a teoria da pecking-order pressupõe uma relação negativa. As empresas mais rendíveis incorrerão em menor probabilidade de insolvência financeira e terão maior capacidade para aproveitar os benefícios fiscais proporcionados pelos juros, pelo que o endividamento as valorizará (Fama \& French, 2002). Jensen (1986) defende que a rendibilidade da empresa pode sinalizar qualidade, o que potenciará uma relação positiva entre esta variável e o endividamento.

Por sua vez, as empresas que registem níveis de rendibilidade superiores, gerarão maior nível de recursos internos e terão menor apetência para o endividamento (Myers, 1984). A hierarquia das fontes de financiamento de Myers (1984) sugere que empresas mais rendíveis tendem a financiar-se com resultados retidos. Caso estes sejam insuficientes, as PME optarão por dívida com a maturidade que menos reduza a flexibilidade dos gestores, ou seja, dívida de curto prazo.

Seguindo Degryse et al. (2012) e Mateev et al. (2013), propõem-se as seguintes relações entre o endividamento e a rendibilidade.

Hipótese 3a: A rendibilidade está negativamente associada com a dívida de longo prazo.

Hipótese 3b: A rendibilidade terá maior impacto negativo na dívida de curto prazo do que na dívida de longo prazo.

\section{Oportunidades de crescimento}

Myers (1977) defendeu que a propensão dos empresários para assumirem riscos perante elevadas oportunidades de crescimento das empresas gerarão custos de agência que se refletirão, particularmente, nos custos de endividamento, conduzindo a uma relação negativa entre as oportunidades de crescimento e o endividamento. Contudo, este problema de agência poderá ser amenizado com o recurso a dívida de curto prazo (Easterwood \& Kadapakkan, 1994).

Por sua vez, a teoria da pecking-order defende uma relação positiva com base no pressuposto de que as oportunidades de crescimento gerarão acrescidas necessidades de fundos e, exauridos os fundos internos, as empresas preferirão dívida a capital próprio, dado que as oportunidades de investimento encerram maior risco do que os ativos tangíveis (Shyam-Sunder \& Myers, 1999).

À semelhança de Hall et al. $(2000 ; 2004)$ e Mateev et al. (2013), formulam-se as hipóteses que se seguem.

Hipótese 4a: As oportunidades de crescimento estão negativamente associadas com a dívida de longo prazo.

Hipótese 4b: As oportunidades de crescimento estão positivamente associadas com a dívida de curto prazo.

\section{Poupança fiscal não associada ao endividamento}

DeAngelo e Masulis (1980) sugerem fontes alternativas ao benefício fiscal dos juros, igualmente geradoras de benefícios, nomeadamente depreciações e amortizações, despesas com investigação e desenvolvimento e crédito fiscal do investimento. As empresas rendíveis com menores níveis de fontes alternativas utilizarão mais dívida do que as menos rendíveis. A teoria do trade-off prevê uma relação negativa entre esses fatores e o nível de endividamento.

Tal como em Michaelas et al. (1999), Sogorb-Mira (2005) e López-Gracia e Sogorb-Mira (2008), formula-se a seguinte hipótese:

Hipótese 5: A poupança fiscal não associada ao endividamento está negativamente associada com a dívida.

\section{Volatilidade}

À luz da teoria da informação assimétrica e da sinalização, Leland e Pyle (1977) defenderam que a maior incerteza dos resultados da empresa dificulta o seu endividamento. À semelhança de Michaelas et al. (1999) e de López-Gracia e Sogorb-Mira (2008), espera-se que a variabilidade dos resultados tenha uma relação negativa com o endividamento, porquanto a maior volatilidade do resultado implicará uma maior probabilidade de incumprimento do serviço da dívida.

Hipótese 6: A volatilidade dos resultados está negativamente associada com a dívida.

\section{Especificidade}

A indústria transformadora agrega diversos setores de atividade que encerram inúmeras especificidades, nomeadamente ao nível dos seus ativos. Matias (2000), com base na teoria dos custos de transação e com dados de empresas portuguesas, sustentou a predição teórica de Williamson (1988) de que a estrutura de capital depende da especificidade dos ativos envolvidos. As empresas com maior especificidade apresentarão menor nível de endividamento porque em situação de insolvência financeira será mais difícil encontrar um mercado secundário competitivo para os seus inventários e equipamentos produtivos (Kim et al., 2006).

Hipótese 7: A especificidade dos ativos está negativamente associada com a dívida.

\section{Idade da empresa}

As empresas já instaladas no mercado tendem a ser mais credíveis, rendíveis e diversificadas do que as mais jovens, pelo que poderão apresentar menor probabilidade de insolvência financeira (Cole, 2013). Estes argumentos 
suportam a predição de uma relação positiva entre a dívida e a idade da empresa à luz da teoria do trade-off.

Por sua vez, a teoria da pecking-order prevê uma relação negativa explicada pelo facto das empresas mais velhas provavelmente terem acumulado maiores níveis de fundos próprios e evidenciarem menores necessidades de capital alheio.

À semelhança de Hall et al. (2000; 2004), neste estudo prevêseuma relação negativa entre a idade da empresa e a dívida.

Hipótese 8: A idade da empresa está negativamente associada com a dívida.

\section{Metodologia}

\subsection{Base de dados, amostra e variáveis}

Os dados utilizados neste estudo foram obtidos através da base de dados Amadeus, disponibilizada por Bureau van
Dijk. As empresas que compõem a amostra satisfazem as condições de PME previstas na Recomendação 2003/361/CE da Comissão de 6 de Maio de 2003. Em termos sintéticos, as empresas apresentam: i) número de trabalhadores inferior a 250 e, ii) volume de negócios menor ou igual a 50 milhões de euros ou balanço total anual menor ou igual a 43 milhões de euros.

Este estudo baseia-se em dados financeiros de uma amostra final composta por 1.488 PME da indústria transformadora portuguesa do período compreendido entre 2004 e 2011, pelo que se obteve um painel com 11.904 observações. Foram removidas as empresas que se encontravam nas seguintes situações: ativo fixo superior ao ativo total líquido; capital próprio com valor negativo; sem informação disponível para todas as variáveis em todos os anos. A Tabela 1 apresenta a discriminação da amostra por setor de atividade.

Tabela 1 - Empresas da Amostra por Divisão da Atividade Económica

\begin{tabular}{|c|c|c|}
\hline Divisão da atividade económica & № & $\%$ \\
\hline 10 Indústrias alimentares & 166 & $11,2 \%$ \\
\hline 11 Indústria das bebidas & 24 & $1,6 \%$ \\
\hline 13 Fabricação de têxteis & 112 & $7,5 \%$ \\
\hline 14 Indústria do vestuário & 116 & $7,8 \%$ \\
\hline 15 Indústria do couro e dos produtos do couro & 71 & $4,8 \%$ \\
\hline 16 Indústrias da madeira e da cortiça e suas obras, exceto mobiliário; fabricação de obras de cestaria e espartaria & 108 & $7,3 \%$ \\
\hline 17 Fabricação de pasta, de papel, cartão e seus artigos & 26 & $1,7 \%$ \\
\hline 18 Impressão e reprodução de suportes gravados & 74 & $5,0 \%$ \\
\hline 20 Fabricação de produtos químicos e de fibras sintéticas ou artificiais exceto produtos farmacêuticos & 28 & $1,9 \%$ \\
\hline 22 Fabricação de artigos de borracha e de materiais plásticos & 56 & $3,8 \%$ \\
\hline 23 Fabricação de outros produtos minerais não metálicos & 111 & $7,5 \%$ \\
\hline 24 Indústrias metalúrgicas de base & 14 & $0,9 \%$ \\
\hline 25 Fabricação de produtos metálicos, exceto máquinas e equipamentos & 296 & $19,9 \%$ \\
\hline 26 Fabricação de equipamentos informáticos, equipamento para comunicações e produtos eletrónicos e óticos & 5 & $0,3 \%$ \\
\hline 27 Fabricação de equipamento eléctrico & 29 & $1,9 \%$ \\
\hline 28 Fabricação de máquinas e equipamentos & 59 & $4,0 \%$ \\
\hline 29 Fabricação de veículos automóveis, reboques, semi-reboques e componentes para veículos automóveis & 19 & $1,3 \%$ \\
\hline 30 Fabricação de outro equipamento de transporte & 7 & $0,5 \%$ \\
\hline 31 Fabricação de mobiliário e de colchões & 114 & $7,7 \%$ \\
\hline 32 Outras indústrias transformadoras & 53 & $3,6 \%$ \\
\hline Total & 1.488 & $100 \%$ \\
\hline
\end{tabular}

Fonte: Elaboração própria.

Para testar o efeito dos determinantes na estrutura de capital, adotam-se proxies que têm sido utilizadas noutros estudos empíricos, nomeadamente nos indicados no início deste trabalho, por exemplo na medição das variáveis volatilidade e especificidade adotaram-se as fórmulas sugeridas por Nunes e Serrasqueiro (2014) e Kim et al. (2006), respetivamente. A Tabela 2 apresenta as variáveis a investigar e as respetivas medidas.

Tabela 2 - Variáveis Dependentes e Independentes

\begin{tabular}{|c|c|c|}
\hline Variáveis & Definição & Medida \\
\hline \multicolumn{3}{|c|}{ Dependentes: } \\
\hline EMLP $_{\mathrm{i}, \mathrm{t}}$ & Endividamento de médio e longo prazo & Passivo não Corrente/Ativo Total \\
\hline $\mathrm{ECP}_{\mathrm{i}, \mathrm{t}}$ & Endividamento de curto prazo & Passivo Corrente/Ativo Total \\
\hline \multicolumn{3}{|c|}{ Independentes: } \\
\hline $\mathrm{DIM}_{\mathrm{i}, \mathrm{t}}$ & Dimensão & Logaritmo natural (Ativo Total) \\
\hline $\mathrm{TANG}_{\mathrm{i}, \mathrm{t}}$ & Tangibilidade & Ativo Tangível/Ativo Total \\
\hline REND $_{\mathrm{i}, \mathrm{t}}$ & Rendibilidade & Resultado Antes de Juros e Impostos/Ativo Total \\
\hline $\mathrm{OPOR}_{\mathrm{i}, \mathrm{t}}$ & Oportunidades de crescimento & (AtivoTotal $_{\mathrm{i}, \mathrm{t}}$-Ativo Total $_{\mathrm{i}, \mathrm{t}-\mathrm{1}}$ )/Ativo Total $\mathrm{i}_{\mathrm{i}, \mathrm{t}-1}$ \\
\hline POUP $_{\mathrm{i}, \mathrm{t}}$ & Poupança fiscal não associada ao endividamento & Depreciações e Amortizações do Período/Ativo Total \\
\hline $\mathrm{VOL}_{\mathrm{i}, \mathrm{t}}$ & Volatilidade dos resultados & $\begin{array}{l}\text { Valor absoluto [(Resultado Antes de Juros e Impostos }{ }_{\mathrm{i}, \mathrm{t}}-\text { Resultado Antes de } \\
\left.\left.\text { Juros e Impostos } \mathrm{S}_{\mathrm{i}, \mathrm{t}-1}\right) / \text { Resultado Antes de Juros e Impostos } \mathrm{S}_{\mathrm{i}, \mathrm{t}-\mathrm{1}}\right]\end{array}$ \\
\hline $\mathrm{ESP}_{\mathrm{i}, \mathrm{t}}$ & Especificidade & Custo das Mercadorias Vendidas e Matérias Consumidas/Vendas \\
\hline IDAD $_{\mathrm{i}, \mathrm{t}}$ & Idade da empresa em anos & Logaritmo natural (ano dos dados -ano da constituição) \\
\hline CRISt $_{t}$ & Crise & Variável dummy: 1 nos anos de 2008 a 2011; 0 nos anos de 2004 a 2007 \\
\hline
\end{tabular}


A estrutura de capital é medida através de duas variáveis dependentes, os rácios de endividamento de médio e longo prazo e de curto prazo. À semelhança de outros estudos não se considerou o rácio de dívida total. Chittenden et al. (1996) demonstraram que o endividamento total encobre os efeitos opostos de algumas variáveis no endividamento de curto prazo e de médio e longo prazo. Todos os rácios são calculados através dos seus valores contabilísticos, únicos disponíveis nas empresas objeto de investigação, de resto Graham e Harvey (2001) observaram que os gestores utilizam os valores contabilísticos quando tomam decisões sobre a estrutura de capital das suas empresas.

\subsection{Estimação do modelo}

Os modelos de dados em painel têm diversas vantagens relativamente aos modelos para dados seccionais, conduzindo à obtenção de estatísticas mais precisas e ao aumento da potência dos testes estatísticos, salientando-se o facto de permitirem a compreensão da relação entre as variáveis em estudo ao longo do tempo e de relevarem a heterogeneidade individual. 0 modelo de regressão linear múltipla de dados em painel utilizado na análise é o seguinte:

$$
Y_{i t}=\beta X_{i t}+\alpha_{i}+\mu_{i t}, \quad i=1, \ldots, 1.488, \quad t=2004, \ldots, 2011
$$

Onde $X_{i t}$ é $1 \times \mathrm{K}$, podendo conter variáveis observáveis que se alteram ao longo de $t$ mas não de $i$, variáveis que se alteram ao longo de $i$ mas não de $t$ e variáveis que se alteram ao longo de $i$ e de $t$. $\alpha_{i}$ mede o efeito individual não observado. $\mu_{i t}$ representa o erro ou distúrbio idiossincrático, variando ao longo de $i$ e de $t$.

O método de estimação escolhido para o teste das hipóteses formuladas é validado através dos testes de White e Wald Modificado (testes à heterocedasticidade), Multiplicador de Lagrange de Breusch e Pagan (LM) (teste aos efeitos individuais das empresas), Robusto de Hausman (teste aos efeitos fixos versus efeitos aleatórios) e Wooldridge (teste à autocorrelação). 0 teste de White assume como hipótese nula variância constante e é aplicado à regressão dos dados agrupados pelo método dos mínimos quadrados ordinários (pooled OLS), o teste de Wald Modificado tem como hipótese nula $\sigma_{i}^{2}=\sigma^{2}$ e testa a heterocedasticidade entre as empresas no modelo de efeitos fixos. 0 teste LM analisa a relevância dos efeitos individuais das empresas com o objetivo de se verificar se o modelo mais adequado na explicação do endividamento das empresas da indústria transformadora é a regressão pelo método dos mínimos quadrados ordinários ou a regressão de dados em painel. A comparação entre o modelo de dados em painel de efeitos fixos e aleatórios é efetuada através do teste de Hausman Robusto, recomendado por Wooldrige (2002) em situações em que se verifica a presença de heterocedasticidade e autocorrelação. 0 modelo de efeitos fixos admite que os efeitos individuais das empresas encontram-se correlacionados com as variáveis explicativas, enquanto o modelo de efeitos aleatórios admite que os efeitos individuais não se encontram correlacionados com as variáveis explicativas. 0 teste de Wooldridge analisa a presença de autocorrelação de primeira ordem nos resíduos em modelos de dados em painel.

\section{Resultados}

\subsection{Estatísticas descritivas e matriz de correlações}

As estatísticas descritivas das variáveis dependentes e independentes são as constantes na Tabela 3. Observa-se que as PME do estudo se financiam especialmente com dívida de curto prazo (67\% do total da dívida é de curto prazo). A dimensão média das PME é de, aproximadamente, 943,2 milhares de euros, variando de um mínimo de 9,5 milhares de euros e um máximo de 34.593,9 milhares de euros, e têm, em média, 17 anos. Os seus ativos tangíveis representam, em média, $34 \%$ do ativo total que cresceu a uma média de $6 \%$ ao ano. As depreciações e amortizações do período atingem, em média, 5,8\% do ativo total. Aproximadamente $45 \%$ do valor das vendas é canalizado para cobrir os custos de mercadorias vendidas e matérias consumidas. Observando os valores dos desvios padrões, é de destacar a forte dispersão em torno da variável volatilidade dos resultados operacionais.

Tabela 3 - Estatísticas Descritivas

\begin{tabular}{|l|c|c|c|c|c|}
\hline \multicolumn{1}{|c|}{ Variável } & Observações & Média & Desvio padrão & Mínimo & Máximo \\
\hline EMLP $_{\mathrm{i}, \mathrm{t}}$ & 11.904 & 0,2074 & 0,1825 & 0,0000 & 0,9869 \\
\hline $\mathrm{ECP}_{\mathrm{i}, \mathrm{t}}$ & 11.904 & 0,4289 & 0,1987 & 0,0000 & 0,9985 \\
\hline DIM $_{\mathrm{i}, \mathrm{t}}$ & 11.904 & 2,9746 & 0,4949 & 0,9772 & 4,5390 \\
\hline TANG $_{\mathrm{i}, \mathrm{t}}$ & 11.904 & 0,3456 & 0,2013 & 0,0000 & 0,9554 \\
\hline REND $_{\mathrm{i}, \mathrm{t}}$ & 11.904 & 1,0842 & 0,5704 & 0,0072 & 6,3461 \\
\hline OPOR $_{\mathrm{i}, \mathrm{t}}$ & 11.904 & 0,0622 & 0,3154 & $-0,9321$ & 21,592 \\
\hline POUP $_{\mathrm{i}, \mathrm{t}}$ & 11.904 & 0,0584 & 0,0469 & 0,0000 & 1,3034 \\
\hline VOL $_{\mathrm{i}, \mathrm{t}}$ & 11.904 & 2,5879 & 38,919 & 0,0000 & 2998,0 \\
\hline ESP $_{\mathrm{i}, \mathrm{t}}$ & 11.904 & 0,4517 & 0,1766 & 0,0002 & 2,8456 \\
\hline IDAD $_{\mathrm{i}, \mathrm{t}}$ & 11.904 & 1,2419 & 0,2739 & 0,0000 & 1,9494 \\
\hline
\end{tabular}

Nota: As variáveis encontram-se definidas na tabela 2.

Fonte: Elaboração própria

A Tabela 4 mostra a matriz de correlações. Ao nível do endividamento de curto prazo existem correlações estatisticamente significativas positivas com as variáveis dimensão, rendibilidade, oportunidades de 
crescimento e especificidade e negativas com tangibilidade, idade e com a variável dummy crise. Ao nível do endividamento de longo prazo existem correlações estatisticamente significativas positivas com as variáveis tangibilidade e crise e negativas com as variáveis dimensão, rendibilidade, oportunidades de crescimento, especificidade e idade. As correlações entre as variáveis independentes são inferiores a 30\%, exceto a correlação entre as variáveis poupança fiscal não associada ao endividamento e tangibilidade e entre idade e dimensão, pelo que segundo Gujarati e Porter (2010) o problema da colinearidade entre essas variáveis não é particularmente relevante.

Tabela 4 - Matriz de Correlações

\begin{tabular}{|c|c|c|c|c|c|c|c|c|c|c|c|}
\hline & $\mathbf{E M L P}_{\mathrm{i}, \mathrm{t}}$ & $\mathbf{E C P}_{\mathrm{i}, \mathrm{t}}$ & DIM $_{\mathrm{i}, \mathrm{t}}$ & TANG $_{\mathrm{i}, \mathrm{t}}$ & REND $_{i, t}$ & OPOR $_{i, t}$ & POUP $_{i, t}$ & $\operatorname{VOL}_{\mathrm{i}, \mathrm{t}}$ & $\mathbf{E S P}_{\mathrm{i}, \mathrm{t}}$ & IDAD $_{i, t}$ & CRIS $_{t}$ \\
\hline $\mathrm{EMLP}_{\mathrm{i}, \mathrm{t}}$ & 1,0000 & & & & & & & & & & \\
\hline $\mathrm{ECP}_{\mathrm{i}, \mathrm{t}}$ & $-0,5338^{* *}$ & 1,0000 & & & & & & & & & \\
\hline DIM $_{i, t}$ & $-0,0567^{* *}$ & $0,0203^{*}$ & 1,0000 & & & & & & & & \\
\hline TANG ${ }_{i, t}$ & $0,2162^{* *}$ & $-0,1391^{* *}$ & $0,1275^{* *}$ & 1,0000 & & & & & & & \\
\hline $\operatorname{REND}_{\mathrm{i}, \mathrm{t}}$ & $-0,2330^{* *}$ & $0,2090^{* *}$ & $-0,2163^{* *}$ & $-0,2032^{* *}$ & 1,0000 & & & & & & \\
\hline $\mathrm{OPOR}_{\mathrm{i}, \mathrm{t}}$ & $-0,0058$ & $0,1036^{* *}$ & $0,0504^{* *}$ & 0,0091 & $-0,0216^{*}$ & 1,0000 & & & & & \\
\hline POUP $_{i, t}$ & 0,0041 & 0,0010 & $-0,0943^{* *}$ & $0,3307^{* *}$ & $0,2205^{* *}$ & $-0,0470^{* *}$ & 1,0000 & & & & \\
\hline $\mathrm{VOL}_{\mathrm{i}, \mathrm{t}}$ & 0,0084 & $-0,0064$ & $-0,0027$ & $-0,0066$ & $-0,0071$ & 0,0018 & 0,0105 & 1,0000 & & & \\
\hline $\mathrm{ESP}_{\mathrm{i}, \mathrm{t}}$ & $-0,0593^{* *}$ & $0,1447^{* *}$ & $0,1343^{* *}$ & $-0,2145^{* *}$ & $0,2024^{* *}$ & $0,0415^{* *}$ & $-0,2251^{* *}$ & 0,0079 & 1,0000 & & \\
\hline $\mathrm{IDAD}_{\mathrm{i}, \mathrm{t}}$ & $-0,0803^{* *}$ & $-0,2012^{* *}$ & $0,3206 * *$ & $-0,0428^{* *}$ & $-0,1099 * *$ & $-0,1061^{* *}$ & $-0,1581^{* *}$ & $0,0222^{*}$ & $-0,0347^{* *}$ & 1,0000 & \\
\hline CRIS $_{\mathrm{t}}$ & $0,0526^{* *}$ & $-0,1409 * *$ & $0,0695^{* *}$ & $-0,0623^{* *}$ & $-0,0852^{* *}$ & $-0,0824^{* *}$ & $-0,1392^{* *}$ & $-0,0135$ & $-0,0296 * *$ & $0.2185^{* *}$ & 1,0000 \\
\hline
\end{tabular}

Notas: 1) as variáveis encontram-se definidas na tabela 2;2) **Significância estatística a 1\%; * Significância estatística a 5\%

Fonte: Elaboração própria.

\subsection{Resultados dos modelos}

Procede-se agora à validação dos diferentes modelos estáticos de dados em painel explicativos do endividamento de médio e longo prazo e do endividamento de curto prazo (Tabelas 5 e 6).

Tabela 5 - Estimadores do Endividamento de Médio e Longo Prazo

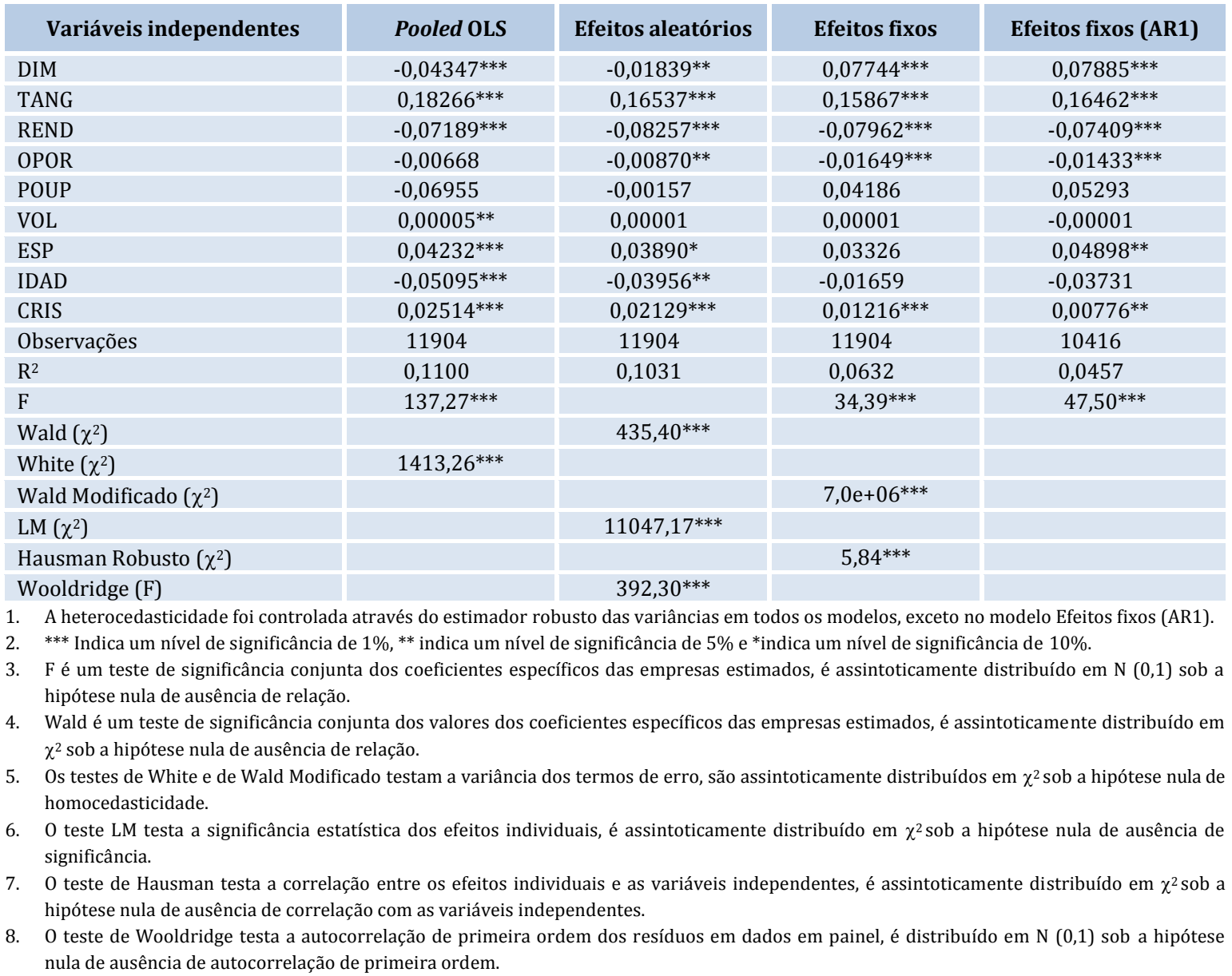

Fonte: Elaboração própria. 


\begin{tabular}{|c|c|c|c|c|c|}
\hline & Variáveis independentes & Pooled OLS & Efeitos aleatórios & Efeitos fixos & $\begin{array}{c}\text { Efeitos fixos } \\
\text { (AR1) }\end{array}$ \\
\hline & DIM & $0,05377^{* * *}$ & $0,05627^{* * *}$ & $0,07236^{* * *}$ & $0,09619^{* * *}$ \\
\hline & TANG & $-0,11723^{* * *}$ & $-0,11237^{* * *}$ & $-0,11895^{* * *}$ & $-0.14622^{* * *}$ \\
\hline & REND & $0,06239 * * *$ & $0,04066^{* * *}$ & $0,02890 * * *$ & $0,01812^{* * *}$ \\
\hline & OPOR & $0,04396^{* * *}$ & $0,03113^{* * *}$ & $0,02595^{* * *}$ & $0,01787^{* * *}$ \\
\hline & POUP & $-0,07395^{* *}$ & $-0,04899$ & $-0,04414$ & $-0,03056$ \\
\hline & VOL & $-0,00002$ & 0,00000 & 0,00000 & 0,00001 \\
\hline & ESP & $0,05447^{* * *}$ & $0,11713^{* * *}$ & $0,16646^{* * *}$ & $0,13308^{* * *}$ \\
\hline & IDAD & $-0,14700^{* * *}$ & $-0,19263^{* * *}$ & $-0,28739^{* * *}$ & $-0,32618^{* * *}$ \\
\hline & CRIS & $-0,03711^{* * *}$ & $-0,03348^{* * *}$ & $-0,02424^{* * *}$ & $-0.01445^{* * *}$ \\
\hline & Observações & 11904 & 11904 & 11904 & 10416 \\
\hline & $\mathrm{R}^{2}$ & 0,1248 & 0,1171 & 0,0947 & 0,0530 \\
\hline I & $\mathrm{F}$ & $165,67 * * *$ & & $46,92^{* * *}$ & $55,49 * * *$ \\
\hline & Wald $\left(\chi^{2}\right)$ & & $586,82^{* * *}$ & & \\
\hline & White $\left(\chi^{2}\right)$ & $1116,61^{* * *}$ & & & \\
\hline & Wald Modificado $\left(\chi^{2}\right)$ & & & $7,7 e+05^{* * *}$ & \\
\hline & $\operatorname{LM}\left(\chi^{2}\right)$ & & $12472,05^{* * *}$ & & \\
\hline & Hausman Robusto $\left(\chi^{2}\right)$ & & & $15,81^{* * *}$ & \\
\hline & Wooldridge (F) & & $407,63^{* * *}$ & & \\
\hline \multicolumn{6}{|c|}{$\begin{array}{l}\text { A heterocedasticidade foi controlada através do estimador robusto das variâncias em todos os modelos, exceto no modelo Efeitos fixos } \\
\text { (AR1). }\end{array}$} \\
\hline 2. & \multicolumn{5}{|c|}{ *** Indica um nível de significância de 1\%, ** indica um nível de significância de 5\% e *indica um nível de significância de $10 \%}$. \\
\hline & \multirow{2}{*}{\multicolumn{5}{|c|}{$\begin{array}{l}\text { F é um teste de significância conjunta dos coeficientes específicos das empresas estimados, é assintoticamente distribuído em N }(0,1) \text { sob a } \\
\text { hipótese nula de ausência de relação. } \\
\text { Wald é um teste de significância conjunta dos valores dos coeficientes específicos das empresas estimados, é assintoticamente distribuído } \\
\text { em } \chi^{2} \text { sob a hipótese nula de ausência de relação. }\end{array}$}} \\
\hline 4. & & & & & \\
\hline 5. & \multicolumn{5}{|c|}{$\begin{array}{l}\text { Os testes de White e de Wald Modificado testam a variância dos termos de erro, são assintoticamente distribuídos em } \chi^{2} \text { sob a hipótese nula } \\
\text { de homocedasticidade. }\end{array}$} \\
\hline 6. & \multicolumn{5}{|c|}{$\begin{array}{l}\text { O teste LM testa a significância estatística dos efeitos individuais, é assintoticamente distribuído em } \chi^{2} \text { sob a hipótese nula de ausência de } \\
\text { significância. }\end{array}$} \\
\hline 7. & \multirow{2}{*}{\multicolumn{5}{|c|}{$\begin{array}{l}\text { O teste de Hausman testa a correlação entre os efeitos individuais e as variáveis independentes, é assintoticamente distribuído em } \chi^{2} \text { sob a } \\
\text { hipótese nula de ausência de correlação com as variáveis independentes. } \\
0 \text { teste de Wooldridge testa a autocorrelação de primeira ordem dos resíduos em dados em painel, é distribuído em N }(0,1) \text { sob a hipótese } \\
\text { nula de ausência de autocorrelação de primeira ordem. }\end{array}$}} \\
\hline & & & & & \\
\hline
\end{tabular}

A rejeição da hipótese de variância constante (testes de White e Wald Modificado) conduziu à necessidade de correção da heterocedasticidade através do estimador robusto das variâncias nos modelos pooled OLS, de efeitos aleatórios e de efeitos fixos. No teste dos efeitos individuais das empresas (LM), a rejeição da hipótese nula de ausência de efeitos individuais relevantes na explicação do endividamento permite concluir que, neste estudo, o método dos mínimos quadrados ordinários não é o mais adequado. 0 endividamento da indústria transformadora portuguesa é influenciado por características individuais das empresas que não são medidas pelas variáveis independentes. 0 teste de Hausman resulta na rejeição do modelo de efeitos aleatórios, significando que os efeitos individuais não observáveis estão correlacionados com as variáveis independentes. Os resultados do teste à autocorrelação sugerem a rejeição da hipótese nula de ausência de autocorrelação de primeira ordem e justificam a apresentação do modelo de efeitos fixos admitindo autocorrelação. Nos restantes modelos, o recurso ao estimador robusto das variâncias faz com que a autocorrelação em micro-painéis não constitua problema pois o estimador é consistente.

Na globalidade dos modelos, a maior parte das variáveis são estatisticamente significativas. Com base nos resultados dos modelos de dados de painel de efeitos fixos, observam-se os seguintes resultados:

- 0 endividamento de médio e longo prazo tem uma relação positiva estatisticamente significativa com a dimensão e a tangibilidade. Por sua vez, essa relação é negativa com a rendibilidade e as oportunidades de crescimento.

- endividamento de curto prazo tem uma relação positiva estatisticamente significativa com a dimensão, a rendibilidade, as oportunidades de crescimento e a especificidade. Por sua vez, essa relação é negativa com a tangibilidade e a idade da empresa.

A variável dummy crise, que capta os efeitos da crise financeira iniciada em 2008, apresenta em todos os modelos relação positiva estatisticamente significativa com o endividamento de médio e longo prazo e negativa com o de curto prazo.

\subsection{Discussão dos resultados}

Os resultados obtidos mostram que os coeficientes da variável dimensão em ambas as regressões, médio e longo prazo e curto prazo, do modelo de efeitos fixos, são positivos, estatisticamente significativos, pelo que não se rejeita a sub-hipótese 1a mas rejeita-se a sub-hipótese 1 b. As empresas de maior dimensão parecem empregar mais dívida, independentemente da sua maturidade. Estes resultados conferem suporte às teorias do trade-off e da pecking-order, corroboram os de outros estudos, como o de Degryse et al. (2012) e de Mateev et al. (2013) e fornecem alguma evidência sobre os problemas de agência e de informação assimétrica com que as empresas de mais pequena dimensão se defrontam, dificultando-lhes o acesso ao crédito. 
A natureza da relação entre a tangibilidade e o endividamento depende do tipo de dívida usada. Especificamente, os ativos tangíveis têm um efeito positivo e significativo no endividamento de médio e longo prazo, mas negativo na dívida de curto prazo, pelo que não se rejeitam as sub-hipóteses formuladas. Os resultados sugerem que os ativos colaterizáveis das PME poderão contribuir para minimizar os problemas de agência e de informação assimétrica com que se deparam. As PME com menos ativos fixos necessitam de contrair mais dívida de curto prazo. Os resultados conferem suporte a ambas as teorias, trade-off $\mathrm{e}$ pecking-order, e sustentam o princípio do equilíbrio financeiro, segundo o qual as empresas financiam o ativo corrente com dívida de curto prazo e o ativo não corrente com fundos de médio e longo prazo. Resultados idênticos foram também encontrados em Hall et al. (2004), SogorbMira (2005), Degryse et al. (2012) e Mateev et al. (2013).

A rendibilidade está negativamente relacionada com o endividamento de longo prazo, mas positivamente com o de curto prazo pelo que não se rejeita a sub-hipótese 3a mas rejeita-se a sub-hipótese $3 \mathrm{~b}$. Estes resultados suportam parcialmente a teoria da pecking-order uma vez que as empresas mais rendíveis tendem a utilizar menos dívida de longo prazo. Ao contrário de Degryse et al. (2012), não há evidência para a suposição de que no caso de insuficiência de resultados retidos, as PME escolherão a dívida que menos reduza a flexibilidade dos gestores, ou seja, dívida de curto prazo. Contudo, a rendibilidade tem um menor impacto na dívida de curto prazo do que na de longo prazo.

Os resultados sugerem que as PME têm dificuldade em financiar o seu crescimento com dívida de médio e longo prazo. Tal como em Sogorb-Mira (2005), registam-se relações estatisticamente significativas, positiva com a dívida de médio e longo prazo e negativa com a de curto prazo, pelo que não se rejeitam as sub-hipóteses $4 \mathrm{a}$ e $4 \mathrm{~b}$.

A relação entre a poupança fiscal não associada ao endividamento e a dívida não é estatisticamente significativa. Os proprietários e gestores das PME não parecem considerar as fontes alternativas ao benefício fiscal dos juros nas suas decisões sobre a estrutura de capital. Este facto não fornece suporte empírico para a hipótese 5 de DeAngelo e Masulis (1980).

A volatilidade dos resultados como proxy do risco do incumprimento não parece ser fator relevante na estrutura de capital das PME, tal como no estudo de López-Gracia e Sogorb-Mira (2008) e Nunes e Serrasqueiro (2014), utilizando, neste caso, idêntica variável. Não existe suporte empírico para a hipótese 6.

A relação entre a especificidade dos ativos e o endividamento é positiva e estatisticamente significativa com a dívida de curto prazo, o que não sucede com a dívida de médio e longo prazo mas somente no modelo de efeitos fixos, pelo que se rejeita a hipótese 7. 0 sinal positivo, também encontrado no estudo de Kim et al., 2006, pode ser interpretado como efeito do período da crise ou motivado pelo facto da variável adotada não constituir uma proxy adequada da estrutura tecnológica da produção. A variável poderá também fornecer informação sobre a margem industrial de vendas. As empresas caracterizadas por colocaram no mercado produtos com menor margem, tenderão a gerar menores resultados e, por conseguinte, maiores necessidades de financiamento, justificando-se assim, à luz da teoria da pecking order uma relação positiva.

A relação entre a idade da empresa e o endividamento é em todos os modelos negativa mas somente é estatisticamente significativa com a dívida de curto prazo, pelo que somente não se rejeita a hipótese 8 na relação com a dívida de curto prazo. Os resultados mostram que as empresas com mais idade provavelmente acumulam maiores níveis de fundos próprios e evidenciam menores necessidades de capital alheio.

Os resultados obtidos relativamente à variável dummy crise sugerem que durante o período da crise, sensivelmente desde 2008, as PME têm aumentado o seu endividamento de médio e longo prazo comparativamente com os anos anteriores. Por sua vez, têm diminuído o seu nível de endividamento de curto prazo. Contudo, como os decréscimos de dívida de curto prazo foram mais acentuados, verificou-se uma diminuição do endividamento global, o que está conforme com o padrão de financiamento adotado pelas empresas após o início da crise (Banco de Portugal, 2010, 2011).

\section{Conclusões e implicações}

O presente estudo permite concluir que os efeitos individuais não observáveis das PME da indústria transformadora portuguesa são importantes na compreensão da estrutura de capital desta indústria, explicando $60 \%$ da variância do endividamento, de médio e longo prazo e de curto prazo, no modelo de dados em painel de efeitos fixos. Este modelo conseguiu explicar melhor o endividamento de curto prazo do que o endividamento de médio e longo uma vez que regista um valor superior no coeficiente de determinação e maior número de relações estatisticamente significativas. 0 endividamento de médio e longo prazo depende positivamente das variáveis dimensão, tangibilidade e crise e negativamente da rendibilidade e das oportunidades de crescimento. Por sua vez, o endividamento de curto prazo depende positivamente das variáveis dimensão, rendibilidade, oportunidades de crescimento e especificidade e negativamente da tangibilidade, da idade da empresa e da crise.

Os resultados obtidos com o endividamento de médio e longo prazo permitem-nos tecer algumas considerações sobre o crescimento da indústria transformadora portuguesa na medida em que este é o tipo de dívida que suporta o investimento das empresas. A relação positiva entre a tangibilidade e a dívida e a relação negativa entre as oportunidades de crescimento e a dívida demonstram que os problemas de agência entre os gestores e os credores são relevantes e têm condicionado o crescimento e a melhoria do desempenho das PME da indústria transformadora portuguesa. Por outro lado, a relação positiva entre a dimensão e a dívida e a relação negativa entre a rendibilidade e a dívida revela que as empresas mais pequenas e menos rendíveis têm maior dificuldade em investir, pelo que o crescimento da indústria transformadora portuguesa pode ser potenciado se estas 
empresas beneficiarem de condições mais vantajosas do que as atuais na obtenção de crédito.

\section{Referências}

Ang, J. S. (1991). Small business uniqueness and the theory of financial management. The Journal of Small Business Finance, 1(1), $1-13$.

Ang, J. S.(1992). On the theory of finance for privately held firms. The Journal of Small Business Finance, 1(3), 185-203.

Banco de Portugal (2010). A Economia portuguesa em 2010. Relatório do Conselho da Administração do Banco de Portugal, Lisboa, Portugal.

Banco de Portugal (2011). A Economia portuguesa em 2011. Relatório do Conselho da Administração do Banco de Portugal, Lisboa, Portugal.

Barnea, A., Haugen, R., \& Senbet, L. (1981). Market imperfections, agency problems, and capital structure: a review. Financial Management, 10(2-3), 7-22.

Bartholdy, J., Mateus, C., \& Olson, D. (2012). Do Portuguese private firms follow pecking order financing? The European Journal of Finance, 21(10-11), 848-866.

Beck, T., Demirgüç-kunt, A., \& Maksimovic, V. (2008). Financing patterns around the world: are small firms different?. Journal of Financial Economics, 89(3), 467-487.

Bhaird, C., \& Lucey, B. (2010). Determinants of capital structure in Irish SMEs. Small Business Economics, 35(3), 357-375.

Bradley, R., Jarrel, G., \& Kim, E. (1984). On the existence of an optimal capital structure: theory and evidence. The Journal of Finance, 39(3), 857-878.

Cassar, G., \& Holmes, S. (2003). Capital structure and financing of SME's Australian evidence. Accounting and Finance, 43(2), 123-147. Chittenden, H. P., Hall, G., \& Hutchinson, P. (1996). Small firm growth, acess to capital markets and financial structure: review of issues and an empirical investigation. Small Business Economics, 8(1), 59-67.

Cole, R. (2013). What do we know about the capital structure of privately held us firms? Evidence from the surveys of small business finance. Financial Management, 42 (4), 777-813.

Constant, R., Osteryoung, J., \& Nast, D. (1991). Asset-based financing and the determinants of capital structure in the small firms. In Advances in Small Business Finance (29-25). Springer Netherlands.

DeAngelo, H., \& Masulis, R. (1980). Optimal capital structure under corporate and personal taxation. Journal of Financial Economics, 8(1), 3-29.

Degryse, H., Goeij P., \& Kappert,P. (2012). The impact of firm and industry characteristics on small firm's capital structure. Small Business Economics, 38(4), 431-447.

Easterwood, J. C., \& Kadapakkam, P. (1994). Agency conflits, issue costs, and debt maturity. Quartely Journal of Business and Economics, 33(3), 69-80.

Fama, E., \& French, K. (2002). Testing trade-off and pecking-order preditions about dividends and debt. The Review of Financial Studies,15(1), 1-33.

Graham, J., \& Harvey, C. (2001). The theory and practice of corporate finance: evidence from the field. Journal of Financial Economics, 60(2), 187-243.

Gujarati, D., \& Porter, D. (2010). Essentials of econometrics (4th edition). New York: McGrawHill International.

Hall, G., Hutchinson, P., \& Michaelas, N. (2000). Industry effects on the determinants of unquoted SME' capital structure. International Journal of the Economics of Business, 7(3), 297-312.

Hall, G., Hutchinson, P., \& Michaelas, N. (2004). Determinants of the capital structures of european SMEs. Journal of Business Finance \& Accounting, 31(5-6), 711- 728.

Harris, M., \& Raviv, A. (1990). Capital structure and the informational role of debt. The Journal of Finance, 45(2), 321-349.

Harris, M., \& Raviv, A. (1991). The theory of capital structure.The Journal of Finance, 46(1), 297-355.

Heyman, D., Deloof, M., \& Ooghe, H. (2008). The financial structure of private held Belgian firms. Small Business Economics, 30(3), 301-313.
Holmes, S., \& Kent, P. (1991). An empirical analysis of the financial structure of small and large Australian manufacturing enterprises. The Journal of Small Business Finance, 1(2), 141-154.

INE (2014). Empresas em Portugal 2012, Instituto Nacional de Estatística, I.P. Lisboa.

Jensen, J. C., \& Meckling, W. H. (1976). Theory of the firm managerial behavior, agency costs and ownership structure. Journal of Financial Economics, 3(4), 305-360.

Jensen, M. C. (1986). Agency costs of free cash flow, corporate finance, and takeovers. American Economic Review, 76(2), 323-329.

Jordan, J., Lowe, J., \& Taylor, P. (1998). Strategy and financial policy in UK small firms. Journal of Business Finance \& Accounting, 25(12), 1-27.

Kim, H., Heshmati, A., \& Aoun, D. (2006). Dynamics of capital structure: The case of Korean listed manufacturing companies. Asian Economic Journal , 20(3), 275-302.

Kraus, A., \& Litzenberger, R. H. (1973). A state-preference model of optimal financial leverage. The Journal of Finance, 33(4), 911-922.

Leland, H., \& Pyle, D. (1977). Informational asymmetries, financial structure, and financial intermediation. Journal of Finance, 32(2), 371-387.

López-Gracia, J., \& Aybar-Arias, C. (2000). An empirical approach to the financial behaviour of small and medium sized companies. Small Business Economics, 14(1), 55-63.

López-Gracia, J.,\& Sogorb-Mira, F. (2008). Testing Trade-off and Pecking-order theories financing SMEs. Small Business Economics, 31(2), 117-136.

Matias, F. (2000). Estrutura do capital e especificidade dos ativos. Tese de doutoramento não publicada. Instituto Superior das Ciências do Trabalho e da Empresa.

Mateev, M., Poutziouris, P., \& Ivanov, K. (2013). On the determinants of SME capital structure in Central and Eastern Europe: a dynamic panel analysis. Research in International Business and Finance, 27(1), 28-51.

Michaelas, N., Chittenden, F., \& Poutziouris, P. (1999). Financial policy and capital structure choise in U.K. SMEs: empirical evidence from company panel data. Small Business Economics, 12(2), 113-130.

Miller, M. H. (1977). Debt and taxes. The Journal of Finance, 32(2), 261-275

Modigliani, F., \& Miller, M. H. (1958).The cost of capital, corporation finance and the Theory of Investment.The American Economic Review, 48(3), 261-297.

Modigliani, F., \& Miller, M. H. (1963). Corporate income taxes and the cost of capital: a correction.The American Economic Review, 53(3), 433-443.

Myers, S. C.(1977). Determinants of corporate borrowing. Journal of Financial Economics, 5(2), 147-175.

Myers, S. C.(1984). The capital structure puzzle.The Journal of Finance, 39(3), 575- 592.

Myers, S. C.,\& Majluf, N. S. (1984). Corporate financing and investment decisions when firms have information that investors do not have? Journal of Financial Economics, 13(2), 187-221.

Nunes, P., \& Serrasqueiro, Z. (2014). Capital structure of portuguese service industries: a panel data analysis. The Service Industries Journal, 27(5), 549-561.

Ross, S. A. (1977). The determination of financial structure: the incentive-signalling approach. The Bell Journal of Economics, 8(1), 23-40.

Scott, J. H. (1976). A theory of optimal capital structure. The Bell Journal of Economics, 7(1), 33-54.

Serrasqueiro, Z., Armada, M., \& Nunes, P. (2011). Pecking-order theory versus trade-off theory: are service SME's capital structure decisions different?. Service Business, 5(4), 381-409.

Shyam-Sunder, L., \& Myers, S. C. (1999). Testing static tradeoff against pecking-order models of capital structure. Journal of Financial Economics, 51(2), 219-244.

Sogorb-Mira, F. (2005). How SME uniqueness affects capital structure: evidence from a 1994-1998 Spanish data panel. Small Business Economics, 25(5), 447-457. 
Voulgaris, F., Asteriou, D., \& Agiomirgianakis, G. (2002). Capital structure, asset utilization, profitability and growth in the Greek manufaturing sector. Applied Economics, 34(11), 1379-1388.

Williamson, 0. (1988). Corporate finance and corporate governance. The Journal of Finance, 43(3), 567-591.

Wooldridge, J. (2002). Econometric analysis of cross section and panel data. London: MIT Press.

Zhang, Y.(2010). The product category effects on capital structure: evidence from the SMEs of British manufacturing industry. International Journal of Business and Management, 5(8), 86- 112.

Submetido: 14.06 .2014

Aceite: 26.11 .2014 